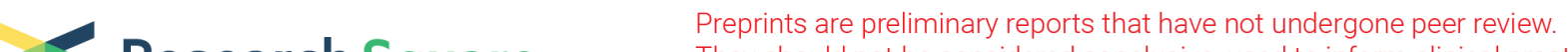 Research Square
They should not be considided conclusive, used to inform clinical practice,
or referenced by the media as validated information.
}

\section{The Root Endophytic Fungus Serendipita indica Decreased the Phytotoxicity of Zinc Oxide Nanoparticles to Alfalfa (Medicago sativa L.)}

\section{Leila Tabande}

Shiraz University School of Agriculture

Mozhgan Sepehri ( $\sim$ m.sepehri@shirazu.ac.ir)

Shiraz University https://orcid.org/0000-0003-1190-9407

Jafar Yasrebi

Shiraz University School of Agriculture

Mehdi Zarei

Shiraz University School of Agriculture

Reza Ghasemi-Fasaei

Shiraz University School of Agriculture

Behnam Khatabi

University of Maryland Eastern Shore

\section{Research Article}

Keywords: Metal-based nanomaterials, Oxidative Stress, Antioxidant Enzymes, Soil Beneficial Microorganisms

Posted Date: February 23rd, 2021

DOl: https://doi.org/10.21203/rs.3.rs-219701/v1

License: @ (i) This work is licensed under a Creative Commons Attribution 4.0 International License. Read Full License 


\section{Abstract}

Zinc oxide nanoparticles (ZnO-NPs) are among the most commonly used nano-fertilizers (NF). However, elevated levels of ZnO-NPs in soil may affect plant growth and development due to its potential toxicity when accumulated in large amounts in plant tissues. This research was conducted using an in situ rhizobox system with the aims of evaluating Zinc uptake from nano-zinc oxide amended rhizosphere soil by alfalfa plant and the effect of plant growth promoting microorganisms on alleviating the phytotoxicity of ZnO-NPs. Treatments included microbial inoculations (Sinorhizobium meliloti, Serendipita indica) and different ZnO-NPs concentrations $\left(0,400\right.$ and $\left.800 \mathrm{mg} \mathrm{Kg}^{-1}\right)$ with three replications. The results indicated that $S$. indica minimized the phytotoxicity of ZnO-NPs to alfalfa by enhancing growth rate and decreasing Zinc (Zn) translocation from root to shoot. Compared with plants inoculated with $S$. meliloti, co-inoculation with $S$. indica increased the shoot dry weight by $18.33 \%$ and $8.05 \%$ at 400 and $800 \mathrm{mg} \mathrm{Kg}^{-1} \mathrm{ZnO}$-NPs. However, at the highest level of ZnONPs $\left(800 \mathrm{mg} \mathrm{kg}^{-1}\right)$, root inoculation of $S$. indica and $S$. indica $+S$. meliloti decreased $\mathrm{Zn}$ transfer factor by $60.2 \%$ and $44.3 \%$ compared to $S$. meliloti, respectively. Furthermore, a distinct relation between tolerance of $S$. indica-colonized plant to ZnO-NPs and the ability of $S$. indica in inhibiting or retarding degradation of polyunsaturated lipids through prevention of excess reactive oxygen species formation was observed. Malondialdehyde content of inoculated plants with $S$. indica either alone or in combination with $S$. meliloti was significantly lower than non-inoculated plants $(p<0.01)$. Zn-induced oxidative stress was mitigated by $S$. indica through enhanced activities of catalase and peroxidase enzymes. The findings of the present study indicate the potential use of endophytes fungus $S$. indica for ensuring food safety and security, and human health in heavy metal-polluted soil by reducing the phytoavailability of heavy metals in the aerial parts of the host plants.

\section{Introduction}

Agriculture sector is facing an intense pressure for achieving considerable efficiency in food production to feed the consistently growing human population (Fróna et al. 2019). With the limited arable lands and scarce agricultural resources, further growth, or even maintenance of current yield levels will depend crucially on increased consumption of organic and mineral fertilizers (Hafeez et al. 2013). However, this approach has resulted in serious deterioration of ecosystems and environment especially in the developing countries with heavy dependence on agriculture for employment, income and food supplies.

Adverse environmental impacts of high rates of mineral fertilizers used in low-input agricultural systems has been triggered a renewed interest in enhancing fertilizer use efficiency (Rahman and Zhang 2018). In this sense, nanotechnology through Nano-fertilizers (NFs) has provided a new frontier in sustainable agriculture systems that promises to enhance the nutrient use efficiency of inputs and minimize relevant problems (He et al. 2019). Certain specific properties of NFs which facilitate nutrient use efficiency are enhanced mobility of NFs due to very small size (less than $100 \mathrm{~nm}$ ) and high solubility in water that increase availability of encapsulated nutrients inside the NFs in rhizosphere (Jampilek and Král'ová 2015).

Plant growth and several physiological processes are highly dependent on zinc ( $\mathrm{Zn}$ ) because of its fundamental role in biochemical and metabolic processes such as photosynthesis, respiration, nucleic acid synthesis and protein, carbohydrate and lipid metabolism (Auld 2001). Moreover, Zn plays a central role in 
detoxification mechanisms in plants such as the reactive oxygen species (ROS) related pathways (Broadley et al. 2007). Fertilizers with oxides $(\mathrm{ZnO})$ and sulfates $\left(\mathrm{ZnSO} 4 \cdot \mathrm{H}_{2} \mathrm{O} \& \mathrm{ZnSO} 4 \cdot 7 \mathrm{H}_{2} \mathrm{O}\right)$ forms improves soil productivity, however, high utilization of zinc fertilizers in soils with low plant available Zn, would result in over supplying $\mathrm{Zn}$ and causes toxicity to plants, and humans, as well as soil microbes (Kabata-Pendias 2010).

Zinc oxide nano-fertilizer is among the most commonly used metal-based nano materials in agriculture to alleviate Zn deficiency in soils (Rajput et al. 2018). New reports show that ZnO-NPs have the potential for delivering Zn via soil or leaves with increased and stimulated crop yield and Zn use efficiency; e.g., rice, maize, wheat, sugarcane, sunflower and cowpea (Bandyopadhyay et al. 2014; Li et al. 2012; Moghaddasi et al. 2017; Monereal et al. 2016; Wang et al. 2013). However, despite the exciting outcomes of nano-fertilizers, increased application of ZnO-NPs may result in appearance of toxicity in plants, animals, human and malfunctioning of soil microbial communities (Chai et al. 2015; Lin and Xing 2007, 2008). For plants this happens when Zn concentrates at the root surface and subsequently internalizes and accumulates in large amounts in plant tissues (Ma et al. 2010). The interaction of plant cell with nanoparticles leads to changes in transcription profile of genes and associated biological pathways which eventually affect plant growth and development (García-Sánchez et al. 2015; Moreno-Olivas et al. 2014). The phytotoxicity of ZnO-NPs on plant physiological traits like seed germination, biomass, leaf number, and root elongation have been reported in many agricultural crops (Monreal et al. 2016). Also, the negative impacts of ZnO-NPs may include oxidative damages to biological membranes (Kim et al. 2012; Mukherjee et al. 2014; Noori et al. 2020), decreased photosynthetic rate (Barhoumi et al. 2015; Mukherjee et al. 2014; Wang et al. 2016) and decrease in plant growth hormones synthesis (Castiglione et al. 2011; Vankova et al. 2017).

Although the quantity of nanomaterials currently reaching the soil is relatively small, however, increase of metal-based nanomaterials $\left(\mathrm{TiO}_{2}, \mathrm{Fe}_{2} \mathrm{O}_{3}, \mathrm{ZnO}\right)$ due to application of pesticides, insecticides and fungicides in soil is expected which may be taken up by roots and ultimately entered into food chain (Rico et al. 2011).

Heavy metal tolerant-plant growth promoting (HMT-PGP) microbes ensure plant survival and growth in contaminated soils by modulating plant growth, altering physico-chemical properties of soil to enhance metal bioavailability and binding metal ions present in the external environment on the cell surface or transport them into the cell (Mishra et al. 2017). Selected strains of rhizosphere Plant Growth Promoting Bacteria (PGPB) and Plant Growth Promoting Fungi (PGPF) contribute to plant protection from toxicity of metal-based NP as they perform multiple functions such as improvement of soil quality, enhancement of plant growth, detoxification, and removal of HM from soil (Mishra et al. 2017; Sepehri and Khatabi 2020). Rhizobia are among the most important PGPB found in the rhizosphere with ability to fix nitrogen in agricultural systems through the symbiotic association with legumes (Hao et al. 2014). In case of PGPF, root entophytic fungus, Serendipita indica formerly known as Piriformospora indica (Singhal et al. 2017) contributes to growth enhancement of host plants growing in harsh environmental conditions (Liu et al. 2020).

Although studies have investigated the ability of HMT-PGP microbes to alleviate toxicity of metal oxide particles such as ZnO on the host plants, however, the potential effects of PGP microorganisms in improving plant growth and development in soils contaminated with metal-based NPs have not yet been completely elucidated for most NPs. Also, it is well documented that PGPB and PGPF cangreatly affect the immobilization of heavy metals by secreting organic acids, siderophores, 1-aminocyclopropane- 1-carboxylic (ACC)- 
deaminase, phytohormones and enzymatic transformation (Rizwan et al. 2016; Sharma and Archana 2016; Vimal et al. 2017).

Therefore, the main objective of the current study is to evaluate phototoxicity of nanoparticulate ZnO (nano$\mathrm{ZnO}$ ) to alfalfa and the synergistic action of PGPB (Sinorhizobiummeliloti) and PGPF (Serendipita indica) to boost plant performance in Zn-contaminated rhizospheric soils.

\section{Materials And Methods}

\section{Characteristics of ZnO-NPs}

Zinc oxide nanoparticles (ZnO-NPs) of $10 \mathrm{~nm}$ mean diameter were obtained from the Iranian Nanomaterials Pioneers Company, NANOSANY (Mashhad, Iran). The sample of nano-zinc oxide was characterized under a transmission electron microscope (TEM) (EM208S, Philips) coupled with X-ray powder diffraction (XRD) (EQUINOX 3000, France) (Graphical abstract). ZnO-NP suspensions with concentration of 400 and $800 \mathrm{mg} \mathrm{I}$ were prepared, and carefully sonicated before mixed with the soil to minimize the aggregation effect.

\section{Soil Sampling for Greenhouse Experiment}

Soil samples were collected from the $0-30 \mathrm{~cm}$ top layer of the agricultural fields located in Agricultural Research Station at Shiraz University, Shiraz-Iran. The soils were homogenized, sieved ( $<2 \mathrm{~mm})$ and analyzed for physio-chemical properties. The soil was sterilized by placing it in an autoclave $\left(25 \mathrm{~min}\right.$ at $\left.121^{\circ} \mathrm{C}\right)$ to eradicate any initial microbial community. Before seeds were transplanted into the soil, a dispersion of deionized water and ZnO-NPs were added to the soil with 0 (control), 400 and $800 \mathrm{mg} \mathrm{Zn} \mathrm{kg}^{-1}$ concentrations (dry based).

\section{Bacterial and Fungal Inoculums}

S. indica was cultured on CM (complex medium) and the spore suspension was collected after 4 weeks of fungal incubation at $24^{\circ} \mathrm{C} \pm 1^{\circ} \mathrm{C}$ in dark. Fungal inoculum was prepared by scratching the surface of CM medium with a mixture of sterile distilled water and Tween-20 (20 ml water and $10 \mu \mathrm{l}$ Tween-20). The suspension of spores was filtered through Miracloth (CalBiochem, Bad Soden, Germany) to remove excess medium, and then washed three times with distilled $\mathrm{H}_{2} \mathrm{O}$ containing Tween-20. After each washing step, the sporeswere collected by centrifugation at $4000 \mathrm{rpm}$ for $7 \mathrm{~min}$. The spore pellet was finally suspended again in distilled $\mathrm{H}_{2} \mathrm{O}$ and adjusted to $\sim 5 \times 105$ spores $\mathrm{ml}^{-1}$ using a hemocytometer (Ghabooli et al. 2013).

The bacterial isolate was selected among the superior Sinorhizobium strains previously screened based on their ability to produce 1-aminocyclopropane-1-carboxylate (ACC) deaminase, indole-3-acetic acid (IAA), $\mathrm{N}_{2}$ fixation and siderophore production. Our studies revealed that the selected strain had nfe, putA, acdS, genes involved in nodulation and symbiotic nitrogen fixation (Talebi et al. 2008). Also, we confirmed that $S$. indica has also ability to produce siderophore and regarded as a siderophore-producing microbe (Sepehri and Khatabi 2020). 
To prepare the bacterial suspension, the bacterium was cultured on Nutrient Broth (NB) medium and incubated for $48 \mathrm{~h}$ and $120 \mathrm{rpm}$ continuous shaking at $28^{\circ} \mathrm{C}$. The bacterial cells were centrifuged at $5000 \mathrm{rpm}$ for $5 \mathrm{~min}$ and the pellets were washed twice with10 mM MgSO4. The bacterial pellets diluted with $10 \mathrm{Mm} \mathrm{MgSO}_{4}$ to make a final concentration of108 CFU ml-1 (Saleem et al. 2017).

\section{Greenhouse Experiment}

The greenhouse experiment was conducted as a completely randomized design with three replicates per treatment at Shiraz University, Shiraz, Iran. Experimental treatments included: ZnO-NPs at three levels mentioned above, and microbial inoculation factor at four levels (control, Serendipita indica, S. meliloti, and $S$. indica+S. meliloti).

The experiment was carried out in 36 rhizobox $(200 \mathrm{~mm} \times 130 \mathrm{~mm} \times 200 \mathrm{~mm})$ based on the design by Wang et al. (2002) with some minor modifications. To separate rhizosphere soil from bulk soil, each rhizobox was subdivided into 3 adjacent compartments by using nylon mesh of $25 \mu \mathrm{m}$ pore size: A central compartment for planting (rhizosphere compartment) and two lateral compartments on both sides (bulk soil). All compartments were filled with soil amended with desired amounts of ZnO-NPs layer by layer using the same filling procedure in all cases. Controls was also set up in three replicates.

Alfalfa (M. saliva L.) seeds of cultivar Hamedani were sterilized for $5 \mathrm{~min}$ in $\mathrm{NaClO}$ solution $(0.75 \% \mathrm{Cl})$ followed by $70 \%$ alcohol for $1 \mathrm{~min}$ and rinsed with sterilized distilled water at least ten times. The seeds were germinated in $45-\mathrm{mm}$ plastic petri plates containing aqueous agar $\left(0.8 \%\right.$ [w/v] agar) at $25^{\circ} \mathrm{C}$ for 2 days. The seedlings were inoculated with $S$. indica by immersion in spore suspension $\left(\sim 5 \times 105\right.$ spores $\left.\mathrm{ml}^{-1}\right)$, and subsequently by gentle shaking (75 rpm) for $3 \mathrm{~h}$. Bacterial inoculation was done by adding $1 \mathrm{ml}$ of $48 \mathrm{~h}$-old bacterial culture $\left(1 \times 108\right.$ bacterial cells $\mathrm{ml}^{-1}$ of broth culture) to the soil surrounding each root seedling using a pipette. In co-inoculation treatment, $S$. meliloti was inoculated in the same manner in rhizoboxs assigned for the study of individual bacterial inoculation 2 days after $S$. indica inoculation. An equal quantity of sterile bacterial and fungal media was added to the control treatment (non-inoculated) to make the treatment conditions uniform.

The inoculated and non-inoculated alfalfa plantlets with bacterial and/or fungal isolates were kept under control growth conditions $\left(26 \pm 1^{\circ} \mathrm{C}\right.$ with $16 / 8 \mathrm{~h}$ light/dark photoperiod and relative humidity of $\left.80-85 \%\right)$. Soil moisture was kept approximately constant (near $70 \%$ field capacity) by periodical watering in order to replace consumed water. No pesticides were applied and weeds were removed manually.

In order to visualize root colonization by $S$. indica microscopically, $S$. indica-inoculated alfalfa roots were harvested 14 days after inoculation. Roots were softened by $10 \% \mathrm{KOH}$ solution for 15 min, acidified with $1 \mathrm{M}$ $\mathrm{HCl}$ for 10 min, and stained with $0.02 \%$ Trypan blue overnight, and then were distained with 50\% lacto-phenol for $1 \mathrm{~h}$ prior to microscopic observation under a light microscope (Dickson and Smith 1998; Phillips and Hayman 1970).

After 9 weeks of ZnO-NPs exposure, the shoots were cut at the crown and leaves washed thoroughly with distilled water before analysis. Subsequently, the collected samples from the last well-developed leaves were frozen at $-80^{\circ} \mathrm{C}$ prior to the evaluation of antioxidant enzymes activities, photosynthetic pigments and MDA 
content. At week 2 of the flowering stage, the plants were harvested and dry weight of shoot and root parts were measured after oven drying samples at $70^{\circ} \mathrm{C}$ for $48 \mathrm{~h}$. The shoot and root concentrations of Zn were determined with Atomic Absorption Spectrophotometer (Perkin-Elmer 3030) according to standard method (Horwitz et al. 1975).

\section{Carotenoids and Chlorophyll Contents}

Carotenoids, chlorophyll a (Chl a) and chlorophyll b ( $\mathrm{Chl} b$ ) of fresh fully expanded leaves were determined based on the Arnon'smethod (Arnon 1967). $0.1 \mathrm{~g}$ of fresh leaf tissues were homogenized in $80 \%$ acetone, centrifuged at $4000 \mathrm{rpm}$ for $20 \mathrm{~min}$ and by using spectrophotometer, the optical density of the supernatant was read at 470, 663 and $645 \mathrm{~nm}$ wave lengths for Carotenoids, Chl a and Chl b, respectively.

\section{Hydrogen Peroxide $\left(\mathrm{H}_{2} \mathrm{O}_{2}\right)$ and Lipid Peroxidation}

Hydrogen peroxide $\left(\mathrm{H}_{2} \mathrm{O}_{2}\right)$ content in control and treated plants was measured according to the method of Nukuntornprakit et al. (2015). About $0.2 \mathrm{~g}$ of fresh leaf tissues from each replicate was homogenized in $2 \mathrm{~mL}$ of $1 \%(\mathrm{w} / \mathrm{v})$ trichloroacetic acid (TCA) and centrifuged at $10,000 \times \mathrm{g}$ for $10 \mathrm{~min}$ at $4^{\circ \mathrm{C}}$. The supernatant $(250 \mu \mathrm{l})$ was mixed with $250 \mu \mathrm{l}$ of phosphate buffer (PBS, $100 \mathrm{mM}, \mathrm{pH}=7$ ) and $500 \mu \mathrm{l}$ of $1 \mathrm{M}$ potassium iodide (KI). The assaymixture was vortexed and its absorbance was measured at $390 \mathrm{~nm}$ using a microplate reader spectrophotometer (Epoch Biotech, USA). The $\mathrm{H}_{2} \mathrm{O}_{2}$ content was determined by using a standard curve of $\mathrm{H}_{2} \mathrm{O}_{2}$ represented as $\mu \mathrm{mol} \mathrm{g} \mathrm{g}^{-1}$ fresh weight.

Lipid peroxidation in terms of malondialdehyde (MDA) formation was determined according to the method of Heath and Packer (1968). $0.1 \mathrm{~g}$ of fresh leaf tissue was homogenized in $0.5 \%$ thiobarbituric acid (TBA) in $20 \%$ trichloroacetic acid (TCA). The assay mixture was heated at $95^{\circ} \mathrm{C}$ in the water bath for $30 \mathrm{~min}$, cooled immediately and centrifuged at $10,000 \times \mathrm{g}$ for $10 \mathrm{~min}$. The absorbance was read at $532 \mathrm{~nm}$. The value of nonspecific absorption at $600 \mathrm{~nm}$ was subtracted. MDA concentration was calculated using an extinction coefficient of $155 \mathrm{mM}^{-1} \mathrm{~cm}^{-1}$ and expressed as nmol g-1 fresh weight.

\section{Antioxidant EnzymesActivities}

Enzyme extraction was performed by grounding $0.5 \mathrm{~g}$ of fresh leaf tissues with $2 \mathrm{~mL}$ of chilled PBS (50 mM, $\mathrm{pH}=7$ ) containing $2 \mathrm{mM}$ ethylenediaminetetraacetic acid (EDTA) and $1 \%(\mathrm{w} / \mathrm{v})$ polyvinylpyrrolidone (PVP). The homogenate was centrifuged at $13,000 \times \mathrm{g}$ for $10 \mathrm{~min}$ at $4^{\circ}{ }^{\circ}$, the supernatant was taken for detection of Catalase (CAT), Peroxidase (POD), and Superoxide dismutase (SOD) activities.

The CAT and POD activities were measured using the method described by Chance and Maehly (1955). CAT activity was determined by adding $50 \mu \mathrm{L}$ of leaf enzyme extract to the reaction medium containing $50 \mathrm{mM}$ PBS $(\mathrm{pH}=7)$ and $15 \mathrm{mM} \mathrm{H}_{2} \mathrm{O}_{2}$ as substrate. Decomposition of $\mathrm{H}_{2} \mathrm{O}_{2}$ was detected by the reduction of absorbance at $240 \mathrm{~nm}$ after $1 \mathrm{~min}$ of reaction. One unit of enzyme activity was defined as a 0.1 change of absorbance per min and it was defined as $\mathrm{U} \mathrm{g}^{-1}$ fresh weight.

POD activity was determined using guaiacol as substrate. The reaction mixture $(3 \mathrm{~mL})$ contained $50 \mu \mathrm{L}$ of crude enzyme extract, $50 \mathrm{mM}$ PBS $(\mathrm{pH}=7), 13 \mathrm{mM}$ guaiacol, and $20 \mathrm{mM} \mathrm{H}_{2} \mathrm{O}_{2}$. Peroxidase activity was detected 
by measuring the absorbance at $470 \mathrm{~nm}$ after 2 min of reaction. One unit of POD activity was defined as the amount of enzyme that caused 0.1 change in absorbance at $470 \mathrm{~nm}$ per min under the specified conditions. The specific POD activity was defined as $\mathrm{U} \mathrm{g}^{-1}$ fresh weight.

SOD activity was measured following the method described by Beachamp and Fridovich (1971). The reaction mixture $(2 \mathrm{~mL})$ contained $100 \mu \mathrm{L}$ of crude enzyme extract in $50 \mathrm{mM}$ PBS $(\mathrm{pH}=7.8)$, including $13 \mathrm{Mm}$ methionine, $75 \mu \mathrm{M}$ nitroblue tetrazolium (NBT), $0.1 \mathrm{mM}$ EDTA, and $2 \mu \mathrm{M}$ riboflavin and was illuminated using a fluorescent lamp for $15 \mathrm{~min}$ at ambient temperature. The absorbance was measured at $560 \mathrm{~nm}$. Two mixtures without enzyme extract were maintained under the dark and light, and used as blank and control, respectively. One unit of SOD activity was detected as the amount of enzyme causing $50 \%$ reduction of NBT and the specific SOD activity was defined as $\mathrm{U} \mathrm{mg}^{-1}$ fresh weight.

\section{Statistical Analysis}

Analysis of variance (ANOVA) of data was performed using SAS 9.1 software. Treatment means were compared by determining the least significant difference (LSD) at $5 \%(p \leq 0.05)$ probability level.

\section{Results}

\section{Soil Characteristics before the Onset of the Experiment}

Geographic locations and some physical and chemical characteristics of the applied soil for the greenhouse experiment are presented in Table 1. The results showed that unlike low organic soil carbon content, the amount of zinc usable was sufficient for the plant and due to low electrical conductivity in the studied soil, there was no salinity problem. Among the chemical characteristics, soil pH is considered as the major variable due to its profound effect on numerous chemical reactions, including essential plant nutrients, phytotoxic elements and pollutants. A high percentage of Iranian arable land as well as the soil used in this experiment, due to high $\mathrm{pH}$ and calcium carbonate equivalent, are calcareous which could have a significant impact on the availability of elements.

\section{Effect of Microbial Inoculation on pH Values in Rhizosphere and Bulk Soil}

The $\mathrm{pH}$ in the rhizosphere soils amended with ZnO-NPs was lower than bulk soil pH (Table 2). The rhizosphere soil pH was significantly lower in microbial treatments over the control (non-inoculated). Among the microbial treatments, the highest $\mathrm{pH}$ value under ZnO-NPs stress recorded in S.meliloti. The root inoculation of $S$. indica either alone or in combination with $S$. meliloti caused a decrease of the rhizosphere soil pH of about 0.5 units compared to the control suggesting that this fungus can help to reduce soil acidity.

\section{Effects of Microbial Inoculation on Plant Biomass}

ZnO-NPs resulted in phenotypic changes as visualized by reduction of shoot and root biomass (Fig. 1\&2). Relative to plants colonized with $S$. indica either alone or in combination with S. meliloti, symptoms of Zn toxicity were noticed on the aboveground and belowground parts of non-inoculated plants and S. meliloti inoculated ones. 
The shoot dry weights of the non-inoculated plants for 400 and $800 \mathrm{mg} \mathrm{Kg}^{-1} \mathrm{ZnO}$-NPs were significantly reduced (by 31.5 and $32.8 \%$, respectively, $p<0.001$ ) compared to non-exposed plants which illustrates Zinc toxicity. This was also observed in tendency for root biomass. At high concentration of ZnO-NPs $\left(800 \mathrm{mg} \mathrm{Kg}^{-1}\right.$ $\mathrm{Zn}$ ), root dry weight of the non-inoculated plants decreased by $45.4 \%$ relative to the control.

S.indica significantly mitigated the adverse effects of $\mathrm{Zn}$ toxicity by displaying significant higher plant growth observed in inoculated plants when compared with non-inoculated and/or inoculated plants with S. meliloti. Zinc toxicity on plants inoculated with $S$. meliloti was clearly visible at all of the applied treatments of ZnONPs. The shoot and root dry weights of $S$. meliloti-inoculated plants decreased $26.1 \%$ and $19.4 \%$ when exposed to $400 \mathrm{mg} \mathrm{Kg}^{-1} \mathrm{ZnO}$-NPs, respectively. A significant reduction in shoot and root weights of plants inoculated with $S$. meliloti were also observed.

Despite the impact of ZnO-NPs on S.meliloti-inoculated plants, S. indica played a major role in decreasing Zn toxicity when inoculated in combination with $S$. meliloti. Compared with the single-inoculation of $S$. meliloti, coinoculated plants exposed to $400 \mathrm{mg} \mathrm{Kg}^{-1} \mathrm{ZnO}-\mathrm{NPs}$ showed an increase of $18.3 \%$ of shoot dry weight.

\section{Photosynthetic Pigments}

The content of Photosynthetic Pigments (carotenoids, chlorophyll a and chlorophyll b) of alfalfa plants were reduced with increasing concentrations of $\mathrm{Zn}$ in both inoculated and non-inoculated plants (Fig. 3).

Under normal conditions, individual inoculation of microbial treatments resulted insignificant increase in chlorophyll a content over the control $(p<0.01)$. S. indica-inoculated plants exposed to ZnO-NPs showedthe highest content of chlorophyll a, chlorophyll b and carotenoids. At the highest level of ZnO-NPs $\left(800 \mathrm{mg} \mathrm{Kg}^{-1}\right)$, S. indica increased the amount of chlorophyll a, chlorophyll b and carotenoids by $17.2 \%, 12.6 \%$ and $11 \%$ compared to non-inoculated plants, respectively. S. meliloti either alone or in combination with S. indica produced similar effects on chlorophyll a and carotenoids, so that no significant difference was detected for different concentrations of ZnO-NPs. In the case of chlorophyll b, double inoculation of S. meliloti and $S$. indica had significant effectfor400 $\mathrm{mg} \mathrm{kg}^{-1} \mathrm{ZnO}-\mathrm{NPs}$, however, the effect of $S$. melilotiwas the same as the controls. The content of chlorophyll b in plants inoculated with $S$. meliloti $+S$. indica at $400 \mathrm{mg} \mathrm{kg}^{-1} \mathrm{ZnO}$-NPs treatment was increased by $12.4 \%$ when compare to $S$. meliloti-colonized plant. The effect of co-inoculation of $S$. meliloti with $S$. indicaon chlorophyll b at the highest concentration of ZnO-NPs showed no significant differences to non-inoculated plants.

\section{Zinc Accumulation in Plant Tissues}

Zinc concentration in the shoot and root parts of both inoculated and non-inoculated alfalfa plant was significantly increased by increasing Zn concentration.S. indica-inoculated plants exposed to 400 and $800 \mathrm{mg}$ $\mathrm{Kg}^{-1} \mathrm{ZnO}$-NPs had the lowest amount of $\mathrm{Zn}$ in the shoot tissue (Fig. 4a). Co-inoculation of $S$. indica and $S$. meliloti at the level of $400 \mathrm{ZnO}-\mathrm{NPs}$ showed no significant difference compared to the individual inoculation of S. meliloti. However, at level of $800 \mathrm{mg} \mathrm{kg}^{-1} \mathrm{ZnO}-\mathrm{NPs}$, the concentration of $\mathrm{Zn}$ in the shoot of plants coinoculated with $S$. meliloti and $S$. indica was significantly lower than the plants inoculated with $S$. meliloti $(p<0.001)$. 
Upon exposure to $400 \mathrm{mg} \mathrm{Kg}^{-1} \mathrm{ZnO}-\mathrm{NPs}$, Zn content inthe roots colonized with the individual inoculations of microbial treatments was significantly higher than the other treatments. At the highest level of ZnO-NPs (800 $\mathrm{mg} \mathrm{kg}^{-1}$ ), co-inoculation of $S$. indica and $S$. meliloti led to an increase in root $\mathrm{Zn}$ concentration, while $S$. meliloti inoculation had no effect on $\mathrm{Zn}$ accumulation when compared to the control plants (Fig. $4 b$ ).

\section{Zinc Transfer Factor (TF)}

The influence of the microbial inoculation on plant $\mathrm{Zn}$ uptake and translocation was further scrutinized by calculating the translocation factor (TF) values (Fig. 5). Increasing concentrations of ZnO-NPs had no significant effect on the TF in $S$. indica treatment, while the TF of plants inoculated with $S$. meliloti increased with the increasing level of ZnO-NPs.

There was a significant difference in TF values between the non-inoculated and inoculated plants under different ZnO-NPs treatments. When plants exposed to $400 \mathrm{mg} \mathrm{kg}^{-1} \mathrm{ZnO}-\mathrm{NPs}$, all microbial inoculations significantly decreased TF compared to the non-inoculated plants. Under such conditions, co-inoculation of $S$. indica and $S$. melilotiled to a relatively high TF, while $S$. indica inoculation showed the lowest TF value. The value of TF in S. indica+ S. meliloti treatment was 152 and $73.9 \%$ higher than the values obtained for individual inoculation of $S$. indica and $S$. meliloti.

At the highest Zn level ( $\left.800 \mathrm{mg} \mathrm{kg}^{-1} \mathrm{ZnO}-\mathrm{NPs}\right)$, S. meliloti inoculation significantly increased the TF of Zn by $60.2 \%$ and $44.3 \%$ compared to $S$. indica either alone or in combination with $S$. meliloti. However, there was no significant difference between plants inoculated with either S. indica or S. indica+ S. meliloti.

\section{Malondialdehyde (MDA) and Hydrogen peroxide $\left(\mathrm{H}_{2} \mathrm{O}_{2}\right)$ Production}

The variation in Malondialdehyde (MDA) content as an index of lipid peroxidation in leaves of alfalfa plants is shown in (Fig. 6a). Comparison between inoculated plants illustrated that ZnO-NPs application caused a significant increase in MDA content of plants inoculated with $S$. meliloti. Upon exposure to $400 \mathrm{mg} \mathrm{Kg}^{-1} \mathrm{ZnO}$ NPs, MDA content of S. meliloti-inoculated plants increased by $39.9 \%$ and $33.5 \%$ compared to plants inoculated with $S$. indicaand $S$. meliloti+S. indica, respectively. However, no significant difference was detected between S. meliloti-inoculated and control plants exposed to 400 and $800 \mathrm{mg} \mathrm{Kg}^{-1} \mathrm{ZnO}-\mathrm{NPs}$.

MDA contentof non-inoculated plants was significantly higher than inoculated plants with $S$. indica either alone or in combination with $S$. meliloti. Although there was no significant difference between plants inoculated with either $S$. indica or $S$. meliloti+S. indica, the rate of decline in MDA content was high for $S$. indica.

As shown in the Fig. $6 \mathrm{~b}$, there was no significant change in the $\mathrm{H}_{2} \mathrm{O}_{2}$ formation in shoots of inoculated plants exposed to $400 \mathrm{mg} \mathrm{Kg}^{-1} \mathrm{ZnO}$-NPs when compared to non-inoculated plants. However, a significant decrease in $\mathrm{H}_{2} \mathrm{O}_{2}$ formation was observed in plants inoculated with $\mathrm{S}$. indica alone or in combination with $S$. meliloti compared to $\mathrm{S}$. meliloti-inoculated plants upon exposure to $800 \mathrm{mg} \mathrm{Kg}^{-1} \mathrm{ZnO}-\mathrm{NPs}$. The amount of $\mathrm{H}_{2} \mathrm{O}_{2}$ production in plants inoculated with S. meliloti+S. indica decreased by $41.2 \%$ compared to inoculated plants with S. meliloti. 


\section{Antioxidant Enzymes}

For the two applied levels of ZnO-NPs, all microbial treatments either alone or in combination exhibited no significant difference on activity of SOD. It's worth to mention that under the highest concentration of ZnO-NPs $\left(800 \mathrm{mg} \mathrm{Kg}^{-1}\right)$, the activity of SOD in the leaves of inoculated plants did not significantly differ from the controls (Table 3). The highest activity of CAT and POD antioxidant enzymes under 400 and $800 \mathrm{mg} \mathrm{Kg}^{-1} \mathrm{ZnO}$ NPs treatments was observed in plants inoculated with $S$. indica. The effect of co-inoculation of $S$. indica with S. melilotion CAT activity was the same as $S$. meliloti if compared with the controls (non-inoculated) at $400 \mathrm{mg}$ $\mathrm{Kg}^{-1} \mathrm{ZnO}$-NPs. However, at $800 \mathrm{mg} \mathrm{Kg}^{-1} \mathrm{ZnO}$-NPs, the lowest CAT activity was found for $\mathrm{S}$. meliloti-inoculated plants. The activity of CAT in inoculated plants with $S$. meliloti decreased by $38.8 \%$ and $23.4 \%$ compared with S. indica and S.meliloti+S. indica treatments, respectively. The highest POD activity was found for $S$. indica colonized plants at the level of $400 \mathrm{mg} \mathrm{Kg}^{-1} \mathrm{ZnO}-\mathrm{NPs}$, which was about $87.6 \%$ and $39.4 \%$ higher than $S$. meliloti and $S$. indica+ S. meliloti, respectively. The POD activity was preferentially stimulated by $S$. indica, while $S$. mliloti and co-inoculation of the microbes produced similar effects on the POD activity at the highest level of $\mathrm{Zn}$ (800 $\left.\mathrm{mg} \mathrm{Kg}^{-1} \mathrm{ZnO}-\mathrm{NPs}\right)$. However, no significant difference was detected between individual inoculation of $S$. indica and inoculation of this fungus with $S$. meliloti under such conditions.

\section{Discussion}

Rhizosphere soil possess different chemical and biological characteristics compared to bulk soil which can alter heavy metals (HM) bioavailability and plant HM uptake (Motaghian and Hosseinpur 2013). The changes in chemical properties of rhizosphere compared to bulk soil, might be due to the changes in $\mathrm{pH}$ induced by plant exudates, microbial activity or a combination of these (Seshadri et al. 2015).

The results showed that the value of $\mathrm{pH}$ in post-harvest rhizosphere soils of both non-inoculated and inoculated plants with the microorganisms was slightly lower than the initial $\mathrm{pH}$ and the value in the bulk soil (Table 2). The lower $\mathrm{pH}$ of the rhizosphere compared to the bulk soil explains possible functions of the large proportion of root exudates (including sugars, amino acids, and organic acids) in attracting microbes to the root that facilitates plant-microbe interactions in the rhizosphere (Sasse et al. 2018). Under metal-stressed conditions, secretion of root exudates containing certain secondary metabolites into the rhizosphere is a detoxification strategy of the plants to tolerate and encounter HM toxicity (Bais et al. 2006). We observed a relationship between rhizosphere soil $\mathrm{pH}$ and $\mathrm{Zn}$ uptake by plant roots indicating that $\mathrm{pH}$ is a principal factor influencing the mobility and bioavailability of heavy metals (Pikuła and Stępień 2007). By comparing pH values inthe rhizosphere soils of the inoculated plants, we demonstrated that $S$. indica inoculation alone or in combination with $S$. meliloti had a substantial influence on decreasing $\mathrm{pH}$ under normal and $\mathrm{Zn}$ stress conditions. One potential explanation is that $S$ indica inoculation greatly affected the organic acid exudation rate and the composition of root exudates. It has been reported that $S$. indica directly increases plant root biomass by producing indole-3-acetic acid (IAA), which increases the surface area for secretion of root exudates including organic acidsin rhizosphere (Strehmel et al. 2016). Increased production of ethylene during root colonization by $S$. indica is another factor which contributes to localized soil acidification (Khatabi et al. 2012). The excessive uptake of cations $\left(\mathrm{NH}^{+}\right)$relative to anions $\left(\mathrm{NO}^{-}\right)$by the plants inoculated with $S$. indica $+S$. melilotidue to the increased levels of biologically fixed $\mathrm{N}_{2}$ might be another reason for rhizosphere 
acidification (Hinsinger et al. 2003). Our results indicate the beneficial effects of synergistic interaction between $S$. indica and $S$. meliloti on alfalfa growth and nodulation. Compared with plants inoculated with $S$. meliloti, co-inoculation of this bacterium with $S$. indica increased the shoot dry weight by $18.33 \%$ and $8.05 \%$ at 400 and $800 \mathrm{mg} \mathrm{Kg}^{-1} \mathrm{ZnO}-\mathrm{NPs}$. Our results were consistent with the previous studies which confirmed the beneficial effect of simultaneous inoculation of endophytic fungi and Rhizobiumon the nodulation, nitrogen fixation and growth of legumes (Hazarika et al. 2000; Li et al. 2020; Sampathkumar and Ganeshkumar 2003).

The amount of $\mathrm{Zn}$ accumulation in the root clearly implies that $S$. indica could effectively increase $\mathrm{Zn}$ bioavailability to the plant root. To prove the influence of $S$. indicaon localized soil acidification and subsequently $\mathrm{Zn}$ bioavailability to the plant root, $\mathrm{Zn}$ concentration in plant roots was measured. The results indicated that at the highest level of ZnO-NPs level $\left(800 \mathrm{mgkg}^{-1}\right)$, individual and co-inoculation of the endophytic fungus $S$. indica with $S$. meliloti significantly increased $Z n$ concentration in roots when compared with plants colonized by $S$. meliloti alone. One explanation could be that tolerance mechanisms adopted by $S$. indica-inoculated plants to counteract excess $\mathrm{Zn}$ toxicity primarily include exclusion mechanisms that impede the entry of $Z n$ ions to the root cells by secreting root exudates in the rhizosphere (Strehmel et al. 2016). In addition, the induction of siderophores synthesisby $S$. meliloti and $S$. indica in the presence of ZnO-NPs can increase the bioavailability of Zn (Sepehri and Khatabi 2020). Here, we showed that the ZnO-NPs toxicity in alfalfa can be modulated by endophytic fungus $S$. indica. The increased growth of plants inoculated with $S$. indica at $800 \mathrm{mg} \mathrm{kg}^{-1} \mathrm{ZnO}$-NPs could be related to the ability of the fungus to produce siderophore which promotes plant growth and nutritional status particularly iron and at the same time enhanced Zn uptake through plant roots. The results also confirm our previous findings about $S$. indicarole in successful survival and growth of alfalfa in cadmium contaminated soils (Sepehri and Khatabi 2020). Also, the high potential of $S$. indica to decrease $\mathrm{Zn}$ translocation from the root to shoot might also contribute to better performance of alfalfa under ZnO-NPs stress. Further studies are necessary to identify the precise mechanism by which $S$. indica takes up high levels of $\mathrm{Zn}$ into the root of the host plant. In addition to the effect of $\mathrm{S}$. indica in decreasing $\mathrm{pH}$ of the studied rhizosphere, the density of fungal myceliumin rhizosphere zone can also play directly to the uptake and translocation of $\mathrm{Zn}$ to the host roots.

On exposure to ZnO-NPs, plants inoculated with S. indica displayed the highest content of chlorophyll a, chlorophyll b and carotenoids. The effect of $S$. indica to enhance plant tolerance to environmental stresses through improved photosynthesis has been well documented (Franken 2012). Several proteomics studies have indicated the significant up-regulation of the key enzymes of the Calvin cycle and the photosynthetic electrontransport chain in the leaves of $S$. indica-inoculated plants under different abiotic stresses (Alikhani et al. 2013; Ghabooli et al. 2013). This study showed the beneficial effect of $S$. indicaon chlorophyll a, chlorophyll $b$ and carotenoid contents of alfalfa grown in contaminated soils with ZnO-NPs. Improved nutritional status in plants inoculated with $S$. indica can lead to increase in biosynthesis of photosynthesis pigments to absorb light energy for photosynthesis (Gao et al. 2008; Gómez-Sagasti 2015; Sepehri and Khatabi 2020). Accumulation of heavy metals in plants will result in induced $\mathrm{H}_{2} \mathrm{O}_{2}$ accumulation and lipid peroxidation which eventually cause oxidative stress (Tripathi, et al. 2012).

This study also revealed that $\mathrm{Zn}$ uptake in alfalfa induced oxidative stress as indicated by the $\mathrm{H}_{2} \mathrm{O}_{2}$ and MDA accumulation data. The enhanced lipid peroxidation in the shoots of the control and inoculated plants with $S$.

Page 11/26 
meliloti exposed to $800 \mathrm{mg} \mathrm{Kg}^{-1} \mathrm{ZnO}$-NPs may be linked to increased $\mathrm{Zn}$ contentin the shoots (Kumari et al. 2011). Low accumulation of MDA in inoculatedplants with individual or combination of $S$. indica and $S$. meliloti treatments clearly demonstrated that the studied microbial treatments could partially counteract ZnONPs stress. The MDA is mainly formed by the ROS-induced degradation of polyunsaturated lipids (Del Rio et al. 2005; Pryor and Stanley 1975). Therefore, a clear relation is provided between the observed tolerance of $S$. indica-colonized plant to ZnO-NPs and the ability of S. indica in inhibiting orretarding degradation of polyunsaturated lipids through preventing excess ROS formation (Sun et al. 2010).

Most abiotic stresses, such as heavy metals pollution can activate a common mechanism involving the production of ROS in plants (Dimkpa et al. 2012; Kim et al. 2009; Ma et al. 2015). The inhibition effects of HM can arise as secondary effects by regulating specific pathways such as antioxidant enzyme systems. The activity of Superoxide Dismutase (SOD) showed similar pattern in S. indica-colonized plants and plants inoculated with other microbial treatments under ZnO-NPs treatments (400 and $800 \mathrm{mg} \mathrm{Kg}^{-1}$ ). In other words, SOD activity showed no significant changes resulted from $S$. indica inoculation. This implies a decreased need in this antioxidant enzyme scavenging reactive oxygen species (ROS) in S. indica-colonized plants. So, we propose that probably the other detoxification related enzymes; CAT and POD are playing greater contribution to counteract oxidative stress in inoculated plants with $S$. indica. These results robustly demonstrated the importance of synergistic impacts of microbial inoculations in protecting alfalfa as the host plant against the negative effects of ZnO-NPs by increasing the activities of POD and CAT as a protective mechanism in scavenging ROS.

\section{Conclusions}

The results indicated that ZnO-NPs affected photosynthesis and plant growth which were accompanied by a significant increase in $\mathrm{Zn}, \mathrm{H}_{2} \mathrm{O}_{2}$ and MDA accumulation. The selected strains of rhizosphere microorganisms especially the endophytic fungus $S$. indica contributed to plant protection from toxicity of ZnO-NPs. The greater root biomass of $S$. indica-colonized plants may be considered as an avoidance mechanism of plants grown in the soils polluted by ZnO-NPs, since it favors the retention of grater $\mathrm{Zn}$ ions in the root interface and thereby restricts the amount of $Z n$ reaching the leaves.We observed a significant decrease of the rhizosphere soil $\mathrm{pH}$ upon root inoculation of alfalfa with $S$. indica either alone or in combination with $S$. meliloti. Therefore, soil acidification during root colonization by $S$. indica is another factor influences $\mathrm{Zn}$ uptake by plant roots. Furthermore, with regards to the $\mathrm{Zn}$ concentrations found in root tissue of $S$. indica-inoculated plants, simultaneously having high biomass production and tolerance against ZnO-NPs toxicity, we confirmed that $S$. indica serve as a highly effective approach in reducing the phyto availability of ZnO-NPs in the aerial parts of the host plants.

\section{Declarations}

\section{Acknowledgements}

The authors are grateful to Shiraz University and Soil and Water Research Institute of Iran (SWRI) for their scientific and technical assistance. 


\section{Compliance with Ethical Standards}

Conflict of Interest: The authors declare that they have no conflict of interest.

Ethics Approval: This article does not contain any studies with human or animal subjects.

Funding: Partial financial support was received from Shiraz University.

Authors' contribution: LT performed the experiments, analyzed data and wrote the first draft of the manuscript. MS supervised the research, participated in its design and gave final approval of the version to be submitted. JY provided technical help in conducting the experiments as a scientific advisor. MZ and RGH-F served as scientific advisors and made a substantial contribution in interpretation of data. BK participated in setting-up the experiments and critically revised the manuscript. All authors read and approved the final version of the manuscript.

Data Availability: The datasets generated during the current study are available from the corresponding author on reasonable request.

Consent to Participate: Not applicable.

Consent to Participate: Not applicable.

\section{References}

Alikhani M, Khatabi B, Sepehri M, Nekouei MK, Mardi M, Salekdeh GH (2013) A proteomics approach to study the molecular basis of enhanced salt tolerance in barley (Hordeum vulgare L.) conferred by the root mutualistic fungus Piriformospora indica. Mol BioSyst 9(6):1498-1510 https://doi.org/ 10.1039/c3mb70069k

Arnon AN (1967) Method of extraction of chlorophyll in the plants. Agron J 23(1):112-121

Auld DS (2001) Zinc coordination sphere in biochemical zinc sites. In: Maret W (ed) Zinc biochemistry, Physiology, and homeostasis, Springer, Dordrecht, pp 85-127

Bais HP, Weir TL, Perry LG, Gilroy S, Vivanco JM (2006) The role of root exudates in rhizosphere interactions with plants and other organisms. Annu Rev Plant Biol 57:233-266.

https://doi.org/10.1146/annurev.arplant.57.032905.105159

Bandyopadhyay S, Ghosh K, Varadachari C (2014) Multimicronutrient slow-release fertilizer of zinc, iron, manganese, and copper. Int J Chem Chem Eng 2014:1-7. https://doi.org/10.1155/2014/327153

Barhoumi L, Oukarroum A, Taher LB, Smiri LS, Abdelmelek H, Dewez D (2015) Effects of superparamagnetic iron oxide nanoparticles on photosynthesis and growth of the aquatic plant Lemna gibba. Arch Environ Contam Toxicol 68(3):510-520. https://doi.org/10.1007/s00244-014-0092-9

Beauchamp C, Fridovich I (1971) Superoxide dismutase: improved assays and an assay applicable to acrylamide gels. Anal Biochem 44(1):276-287. https://doi.org/10.1016/0003-2697(71)90370-8 
Broadley MR, White PJ, Hammond JP, Zelko I, Lux A (2007) Zinc in plants. New Phytol 173(4):677702. https://doi.org/10.1111/j.1469-8137.2007.01996.x

Castiglione MR, Giorgetti L, Geri C, Cremonini R (2011) The effects of nano-TiO 2 on seed germination, development and mitosis of root tip cells of Vicia narbonensis L. and Zea mays L. J Nanopart Res 13(6):24432449. https://doi.org/10.1007/s11051-010-0135-8

Chai H, Yao J, Sun J, Zhang C, Liu W, Zhu M, Ceccanti B (2015) The effect of metal oxide nanoparticles on functional bacteria and metabolic profiles in agricultural soil. Bull Environ Contam Toxicol 94(4):490-495. https://doi.org/10.1007/s00128-015-1485-9

Chance B, Maehly AC (1955) [136] Assay of catalases and peroxidases. Methods Enzymol 2:764-775. https://doi.org/10.1016/s0076-6879(55)02300-8

Del Rio D, Stewart AJ, Pellegrini N (2005) A review of recent studies on malondialdehyde as toxic molecule and biological marker of oxidative stress. Nutr Metab Cardiovasc Dis 15(4):316-328.

https://doi.org/10.1016/j.numecd.2005.05.003.

Dickson S, Smith SE (1998) Evaluation of vesicular-arbuscular mycorrhizal colonisation by staining. In: Varma A (ed) Mycorrhiza manual, Springer-Verlag, Berlin, pp 77-83

Dimkpa CO, McLean JE, Britt DW, Anderson AJ (2012) Bioactivity and biomodification of Ag, ZnO, and CuO nanoparticles with relevance to plant performance in agriculture. Ind Biotechnol 8(6):344-

357. https://doi.org/10.1089/ind.2012.0028

Franken P (2012) The plant strengthening root endophyte Piriformospora indica: potential application and the biology behind. Appl Microbiol Biotechnol 96(6):1455-1464. https://doi.org/10.1007/s00253-012-4506-1

Fróna D, Szenderák J, Harangi-Rákos M (2019) The challenge of feeding the world. Sustainability 11(20):5816. https://doi.org/10.3390/su11205816

Gao K, Li P, Watanabe T, Walter Helbling E (2008) Combined effects of ultraviolet radiation and temperature on morphology, photosynthesis, and DNA of arthrospira (SPIRULINA) platensis (CYANOPHYTA). J Phycol 44(3):777-786. https://doi.org/10.1111/j.1529-8817.2008.00512.x

García-Sánchez S, Bernales I, Cristobal S (2015) Early response to nanoparticles in the Arabidopsis transcriptome compromises plant defence and root-hair development through salicylic acid signalling. BMC genomics .1-17:(1)16 https://doi.org/10.1186/s12864-015-1530-4

Ghabooli M, Khatabi B, Ahmadi FS, Sepehri M, Mirzaei M, Amirkhani A, Jorrin-Novo JV, Hosseini Salekdeh G (2013) Proteomics study reveals the molecular mechanisms underlying water stress tolerance induced by Piriformospora indica in barley. J Proteomics 94:289-301. https://doi.org/10.1016/j.jprot.2013.09.017.

Gómez-Sagasti MT, Marino D (2015) PGPRs and nitrogen-fixing legumes: a perfect team for efficient Cd phytoremediation?. Front Plant Sci 6:81. https://doi.org/10.3389/fpls.2015.00081 
Hafeez B, Khanif, YM, Saleem M (2013) Role of zinc in plant nutrition-a review. J Exp Agric Int 374-391. https://doi.org/10.9734/ajea/2013/2746

Hao X, Taghavi S, Xie P, Orbach MJ, Alwathnani HA, Rensing C, Wei G (2014) Phytoremediation of heavy and transition metals aided by legume-rhizobia symbiosis. Int J Phytorem .179-202:(2)16 https://doi.org/10.1080/15226514.2013.773273

Hazarika DK, Das KK, Dubey LN, Phookan AK (2000) Effect of Vesicular Arbuscular Mycorrhizal (VAM) fungi and Rhizobium on growth and yield of green gram [Vigna radiata (L.)Wilczek]. J Mycol Plant Pathol 30(3):424426

He X, Deng H, Hwang HM (2019) The current application of nanotechnology in food and agriculture. J Food Drug Anal 27(1):1-21. https://doi.org/10.1016/j.jfda.2018.12.002

Heath RL, Packer L (1968) Photoperoxidation in isolated chloroplasts: I. Kinetics and stoichiometry of fatty acid peroxidation. Arch Biochem Biophys 125(1):189-198. https://doi.org/10.1016/0003-9861(68)90654-1

Hinsinger P, Plassard C, Tang C, Jaillard B (2003) Origins of root-mediated pH changes in the rhizosphere and their responses to environmental constraints: a review. Plant Soil 248(1-2):43-59.

https://doi.org/10.1023/a:1022371130939

Horwitz W, Senzel A, Reynolds H, Park, DL (1975) Official methods of analysis, 12th edn. Association of Official Analytical Chemists, Washington, DC

Jampílek J, Král'ová K (2015) Application of nanotechnology in agriculture and food industry, its prospects and risks. Ecol Chem Eng 22(3):321-361. https://doi.org/10.1515/eces-2015-0018

Kabata-Pendias A (2010) Trace elements in soils and plants. CRC press, Florida

Khatabi B, Molitor A, Lindermayr C, Pfiffi S, Durner J, Von Wettstein D, Kogel KH, Schäfer P (2012) Ethylene supports colonization of plant roots by the mutualistic fungus Piriformospora indica. PLoS One 7(4):e35502. https://doi.org/10.1371/journal.pone.0035502

Kim SH, Baek JH, Song YR, Sin MJ, Lee IS (2009) Characterization and phytotoxicity of Zn, Zn oxide nanoparticles. J. Korean Soc. Environ Eng 31(12):1129-1134

Kim S, Lee S, Lee I (2012) Alteration of phytotoxicity and oxidant stress potential by metal oxide nanoparticles in Cucumis sativus. Water, Air, Soil Pollut 223(5):2799-2806. https://doi.org/10.1007/s11270-011-1067-3

Kumari M, Khan SS, Pakrashi S, Mukherjee A, Chandrasekaran N (2011) Cytogenetic and genotoxic effects of zinc oxide nanoparticles on root cells of Allium cepa. J Hazard Mater 190(1-3):613-

621. https://doi.org/10.1016/j.jhazmat.2011.03.095.

Li JH, Liu XR, Zhang Y, Tian FF, Zhao GY, Yu QLY, Jiang FL, Liu Y (2012) Toxicity of nano zinc oxide to mitochondria. Toxicol Res 1(2):137-144. https://doi.org/10.1039/c2tx20016c 
Li L, Zhu P, Wang X, Zhang Z (2020) Phytoremediation effect of Medicago sativa colonized by Piriformospora indica in the phenanthrene and cadmium co-contaminated soil. BMC Biotechnol 20:1-14.

https://doi.org/10.1186/s12896-020-00613-2

Lin D, Xing B (2007) Phytotoxicity of nanoparticles: inhibition of seed germination and root growth. Environ Pollut 150(2):243-250. https://doi.org/10.1016/j.envpol.2007.01.016

Lin D, Xing B (2008) Root uptake and phytotoxicity of ZnO nanoparticles. Environ Sci Technol 42(15):55805585. https://doi.org/10.1021/es800422x

Liu YANG, Jin-Li CAO, Zou YN, Qiang-Sheng WU, Kamil KUČA (2020) Piriformospora indica: a root endophytic fungus and its roles in plants. Not Bot Horti Agrobot Cluj-Napoca 48(1):1-13.

https://doi.org/10.15835/nbha48111761

Ma C, White JC, Dhankher OP, Xing B (2015) Metal-based nanotoxicity and detoxification pathways in higher plants. Environ Sci Technol 49(12):7109-7122. https://doi.org/10.1021/acs.est.5b00685

Ma X, Geiser-Lee J, Deng Y, Kolmakov A (2010) Interactions between engineered nanoparticles (ENPs) and plants: phytotoxicity, uptake and accumulation. Sci Total Environ 408(16):3053-3061.

https://doi.org/10.1016/j.scitotenv.2010.03.031

Mishra J, Singh R, Arora NK (2017) Alleviation of heavy metal stress in plants and remediation of soil by rhizosphere microorganisms. Front Microbiol 8:1706. https://doi.org/10.3389/fmicb.2017.01706

Moghaddasi S, Fotovat A, Khoshgoftarmanesh AH, Karimzadeh F, Khazaei HR, Khorassani R (2017) Bioavailability of coated and uncoated ZnO nanoparticles to cucumber in soil with or without organic matter. Ecotoxicol Environ Saf 144:543-551. https://doi.org/10.1016/j.ecoenv.2017.06.074

Monreal CM, DeRosa M, Mallubhotla SC, Bindraban PS, Dimkpa C (2016) Nanotechnologies for increasing the crop use efficiency of fertilizer-micronutrients. Biol Fertil Soils 52(3):423-437. https://doi.org/10.1007/s00374015-1073-5

Moreno-Olivas F, Gant VU, Johnson KL, Peralta-Videa JR, Gardea-Torresdey JL (2014) Random amplified polymorphic DNA reveals that $\mathrm{TiO}_{2}$ nanoparticles are genotoxic to Cucurbita pepo. J Zhejiang Univ Sci A 15(8):618-623. https://doi.org/10.1631/jzus.a1400159

Motaghian HR, Hosseinpur AR (2013) Zinc desorption kinetics in wheat (Triticum Aestivum L.) rhizosphere in some sewage sludge amended soils. J Soil Sci Plant Nutr 13(3):664-678. http://dx.doi.org/10.4067/S071895162013005000053

Mukherjee A, Peralta-Videa JR, Bandyopadhyay S, Rico CM, Zhao L, Gardea-Torresdey JL (2014) Physiological effects of nanoparticulate ZnO in green peas (Pisum sativum L.) cultivated in soil. Metallomics 6(1):132-138 https://doi.org/10.1039/c3mt00064h

Noori A, Donnelly T, Colbert J, Cai W, Newman LA, White JC (2020) Exposure of tomato (Lycopersicon esculentum) to silver nanoparticles and silver nitrate: physiological and molecular response. Int J 
Nukuntornprakit OA, Chanjirakul K, van Doorn WG, Siriphanich J (2015) Chilling injury in pineapple fruit: Fatty acid composition and antioxidant metabolism. Postharvest Biol Technol 99:20-26.

https://doi.org/10.1016/j.postharvbio.2014.07.010

Phillips JM, Hayman DS (1970) Improved procedures for clearing roots and staining parasitic and vesiculararbuscular mycorrhizal fungi for rapid assessment of infection. Trans Br Mycol Soc 55(1):158-161. https://doi.org/10.1016/s0007-1536(70)80110-3

Pikuła D, Stępień W (2007) Effect of soil pH on the uptake of heavy metals by plants. Fragm Agronom 2(94):227-237

Pryor WA, Stanley JP (1975) Suggested mechanism for the production of malonaldehyde during the autoxidation of polyunsaturated fatty acids.Nonenzymic production of prostaglandin endoperoxides during autoxidation. J Org Chem 40(24):3615-3617. https://doi.org/10.1021/jo00912a038

Rahman KM, Zhang D (2018) Effects of fertilizer broadcasting on the excessive use of inorganic fertilizers and environmental sustainability. Sustainability 10(3):759. https://doi.org/10.3390/su10030759

Rajput VD, Minkina TM, Behal A, Sushkova SN, Mandzhieva S, Singh R, Gorovtsov A, Tsitsuashvili VS, Purvis WO, Ghazaryan KA, Movsesyan HS (2018) Effects of zinc-oxide nanoparticles on soil, plants, animals and soil organisms: a review. Environ. Nanotechnol Monit Manag 9:76-84.

https://doi.org/10.1016/j.enmm.2017.12.006

Rico CM, Majumdar S, Duarte-Gardea M, Peralta-Videa JR, Gardea-Torresdey JL (2011) Interaction of nanoparticles with edible plants and their possible implications in the food chain. J Agric Food Chem 59(8):3485-3498. https://doi.org/10.1021/jf104517j

Rizwan M, Ali S, Qayyum MF, Ibrahim M, Zia-ur-Rehman M, Abbas T, Ok YS (2016) Mechanisms of biocharmediated alleviation of toxicity of trace elements in plants: a critical review. Environ Sci Pollut Res 23(3):22302248. https://doi.org/10.1007/s11356-015-5697-7

Saleem M, Meckes N, Pervaiz ZH, Traw MB (2017) Microbial interactions in the phyllosphere increase plant performance under herbivore biotic stress. Front. Microbiol 8:41. https://doi.org/10.3389/fmicb.2017.00041

Sampathkumar G, Ganeshkumar A (2003) Effect of AM fungi and Rhizobium on growth and nutrition of Vigna mungo L. and Vingna unguiculata. Mycorrhiza news 14(4):15-18

Sasse J, Martinoia E, Northen T (2018) Feed your friends: do plant exudates shape the root microbiome? Trends Plant Sci 23(1):25-41. https://doi.org/10.1016/j.tplants.2017.09.003

Sepehri M, Khatabi B (2020) Combination of Siderophore-Producing Bacteria and Piriformospora indica Provides an Efficient Approach to Improve Cadmium Tolerance in Alfalfa. Microb Ecol 1-14. https://doi.org/10.1007/s00248-020-01629-z 
Seshadri B, Bolan NS, Naidu R (2015) Rhizosphere-induced heavy metal (loid) transformation in relation to bioavailability and remediation. J Soil Sci Plant Nutr 15(2):524-548. https://doi.org/10.4067/s071895162015005000043

Sharma RK, Archana G (2016) Cadmium minimization in food crops by cadmium resistant plant growth promoting rhizobacteria. Appl Soil Ecol 107:66-78. https://doi.org/10.1016/j.apsoil.2016.05.009

Singhal U, Prasad R, Varma A (2017) Piriformospora indica (Serendipita indica): The Novel Symbiont. In: Mycorrhiza-Function, Diversity, State of the Art, Springer, Cham, pp 349-364

Strehmel N, Mönchgesang S, Herklotz S, Krüger S, Ziegler J, Scheel D (2016) Piriformospora indica stimulates root metabolism of Arabidopsis thaliana. Int J Mol Sci 17(7):1091. https://doi.org/10.3390/ijms17071091

Sun C, Johnson JM, Cai D, Sherameti I, Oelmüller R, Lou B (2010) Piriformospora indica confers drought tolerance in Chinese cabbage leaves by stimulating antioxidant enzymes, the expression of drought-related genes and the plastid-localized CAS protein. J Plant Physiol 167(12):1009-1017.

https://doi.org/10.1016/j.jplph.2010.02.013

Talebi MB, Bahar M, Saeidi G, Mengoni A, Bazzicalupo M (2008) Diversity of Sinorhizobium strains nodulating Medicago sativa from different Iranian regions. FEMS Microbiol Lett 288(1):40-46.

https://doi.org/10.1111/j.1574-6968.2008.01329.x

Tripathi DK, Singh VP, Kumar D, Chauhan DK (2012) Rice seedlings under cadmium stress: effect of silicon on growth, cadmium uptake, oxidative stress, antioxidant capacity and root and leaf structures. Chem Ecol 28(3):281-291. https://doi.org/10.1080/02757540.2011.644789

Vankova R, Landa P, Podlipna R, Dobrev PI, Prerostova S, Langhansova L, Gaudinova A, Motkova K, Knirsch V, Vanek T (2017) ZnO nanoparticle effects on hormonal pools in Arabidopsis

thaliana. Sci Total Environ 593:535-542. https://doi.org/10.1016/j.scitotenv.2017.03.160

Vimal SR, Singh JS, Arora NK, Singh S (2017) Soil-plant-microbe interactions in stressed agriculture management: a review. Pedosphere 27(2):177-192. https://doi.org/10.1016/s1002-0160(17)60309-6

Wang P, Menzies NW, Lombi E, McKenna BA, Johannessen B, Glover CJ, Kappen P, Kopittke PM (2013) Fate of ZnO nanoparticles in soils and cowpea (Vigna unguiculata). Environ Sci Technol 47(23):13822-13830. https://doi.org/10.1021/es403466p

Wang X, Yang X, Chen S, Li Q, Wang W, Hou C, Gao X, Wang L, Wang S (2016) Zinc oxide nanoparticles affect biomass accumulation and photosynthesis in Arabidopsis. Front Plant Sci 6:1243.

https://doi.org/10.3389/fpls.2015.01243

Wang Z, Shan XQ, Zhang S (2002) Comparison between fractionation and bioavailability of trace elements in rhizosphere and bulk soils. Chemosphere 46(8):1163-1171. https://doi.org/10.1016/s0045-6535(01)00206-5

\section{Tables}


Table 1 Some physical and chemical properties of the soil.

\begin{tabular}{|c|c|c|c|c|c|c|c|c|c|c|c|}
\hline \multirow{2}{*}{$\begin{array}{l}\text { Soil } \\
\text { texture }\end{array}$} & \multicolumn{2}{|c|}{ Sample location } & \multirow[t]{2}{*}{$\mathrm{PH}$} & \multirow{2}{*}{$\begin{array}{l}\text { ECe } \\
\text { dS } \\
m^{-1}\end{array}$} & \multirow{2}{*}{$\begin{array}{l}\text { CEC } \\
\mathrm{cmol}^{+} \mathrm{kg}^{-1}\end{array}$} & \multirow{2}{*}{$\begin{array}{l}\mathrm{Zn} \\
\mathrm{mg} \\
\mathrm{Kg}^{-1}\end{array}$} & \multirow{2}{*}{$\begin{array}{l}\text { CCE } \\
\%\end{array}$} & \multirow[t]{2}{*}{ OC } & \multirow[t]{2}{*}{ Clay } & \multirow[t]{2}{*}{ Silt } & \multirow[t]{2}{*}{ Sand } \\
\hline & Longitude & Latitude & & & & & & & & & \\
\hline $\begin{array}{l}\text { Clay } \\
\text { Loam }\end{array}$ & $52 \rrbracket 46^{\prime} \mathrm{E}$ & $\begin{array}{l}29050 \\
N\end{array}$ & 8.2 & 0.35 & 15 & 0.94 & 42.5 & 0.41 & 35.6 & 39 & 25.4 \\
\hline
\end{tabular}

$\mathrm{pH}$ and $\mathrm{EC}_{\mathrm{e}}$ (electrical conductivity) in 1:2.5 soil/water (W/V) suspension, CEC (cation exchange capacity), CCE (calcium carbonate equivalent), OC (organic carbon), Zn (DTPA extractable).

Table 2 Effect of microbial inoculation on pH values in rhizosphere and bulk Soil.

\begin{tabular}{|llcclll|}
\hline \multicolumn{5}{c}{ ZnO NPs $\left(\mathrm{mg} \mathrm{kg}^{-1}\right)$} & \multicolumn{4}{l|}{ ZnO NPs $\left(\mathrm{mg} \mathrm{kg}^{-1}\right)$} \\
\hline \\
\hline
\end{tabular}

Values are expressed as means \pm standard deviation $(n=3)$, different small letters indicate significant difference at 0.05 level.

Table 3 Effect of microbial inoculation on SOD, CAT and POD activities of alfalfa plant leaves grown under ZnO-NPs stress. 


\begin{tabular}{|c|c|c|c|}
\hline \multirow[t]{2}{*}{ Microbe } & \multicolumn{3}{|c|}{ ZnO-NPs (mg Kgه区) } \\
\hline & 0 & 400 & 800 \\
\hline & \multicolumn{3}{|c|}{ SOD activity (U mgه区 FW) } \\
\hline control & $0.259 \pm 0.028 \mathrm{bcde}$ & $0.218 \pm 0.051^{\mathrm{de}}$ & $0.351 \pm 0.006^{\mathrm{ab}}$ \\
\hline S.indica & $0.316 \pm 0.009^{a b c}$ & $0.310 \pm 0.024^{a b c}$ & $0.333 \pm 0.012^{\mathrm{ab}}$ \\
\hline S.meliloti & $0.232 \pm 0.022^{\text {cde }}$ & $0.282 \pm 0.057^{\mathrm{abcd}}$ & $0.358 \pm 0.011^{a}$ \\
\hline \multirow[t]{2}{*}{ S.indica+ S.meliloti } & $0.183 \pm 0.029^{e}$ & $0.317 \pm 0.011^{\mathrm{abc}}$ & $0.3224 \pm 0.023^{\mathrm{abc}}$ \\
\hline & \multicolumn{3}{|c|}{ CAT activity (U gهष FW) } \\
\hline control & $0.147 \pm 0.002^{f}$ & $0.263 \pm 0.016^{\text {cde }}$ & $0.226 \pm 0.034^{\mathrm{e}}$ \\
\hline S.indica & $0.283 \pm 0.007^{b c d e}$ & $0.44 \pm 0.043^{a}$ & $0.432 \pm 0.017^{a}$ \\
\hline S.meliloti & $0.245 \pm 0.018 \mathrm{de}$ & $0.326 \pm 0.028 b c$ & $0.264 \pm 0.020$ cde \\
\hline \multirow[t]{2}{*}{ S.indica+ S.meliloti } & $0.105 \pm 0.002^{f}$ & $0.313 \pm 0.037^{b c d}$ & $0.345 \pm 0.005^{b}$ \\
\hline & \multicolumn{3}{|c|}{ POD activity (U gه $\mathrm{FW}$ ) } \\
\hline control & $2.11 \pm 0.21^{f}$ & $3.53 \pm 0.26^{c d}$ & $3.53 \pm 0.35^{\mathrm{cd}}$ \\
\hline S.indica & $4.36 \pm 0.61 \mathrm{bc}$ & $5.87 \pm 0.03^{a}$ & $5.21 \pm 0.52^{a b}$ \\
\hline S.meliloti & $2.43 \pm 0.11$ ef & $3.13 \pm 0.11 \mathrm{de}$ & $3.81 \pm 0.35^{\mathrm{cd}}$ \\
\hline S.indica+ S.meliloti & $3.66 \pm 0.13^{c d}$ & $4.21 \pm 0.52 b c$ & $4.31 \pm 0.07^{b c}$ \\
\hline
\end{tabular}

For each parameter, values are expressed as means \pm standard deviation $(n=3)$, different small letters indicate significant difference at 0.05 level.

\section{Figures}


$\because \mathrm{ZnO}$ NPs $\left(0 \mathrm{mg} \mathrm{Kg} \mathrm{K}^{-1}\right) \quad \mathrm{ZnO}$ NPs $\left(400 \mathrm{mg} \mathrm{kg}^{-1}\right) \quad \mathrm{ZnO}$ NPs $\left(800 \mathrm{mg} \mathrm{kg}^{-1}\right)$
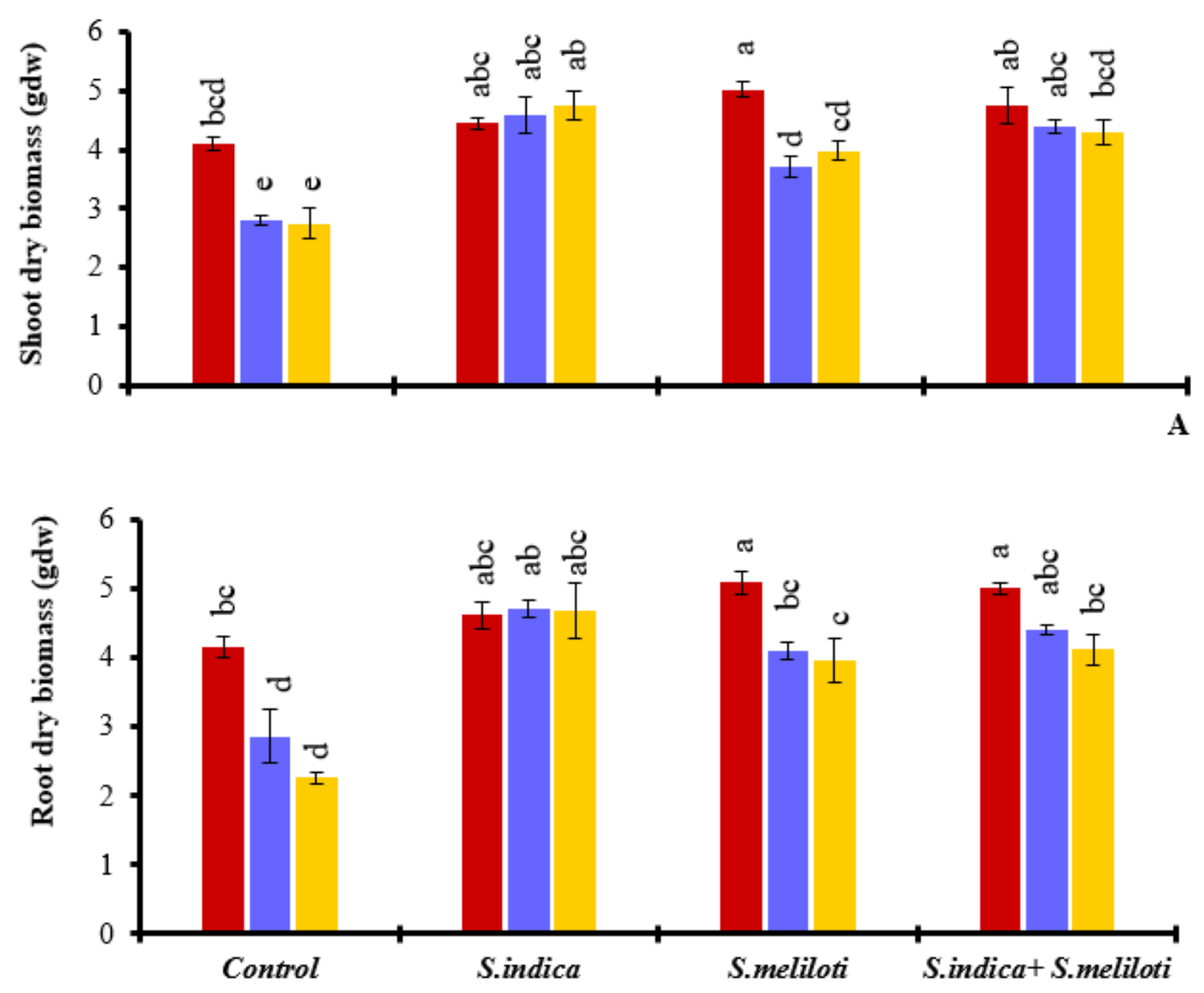

B

Figure 1

Effect of microbial inoculation on the shoot $(\mathrm{A})$ and $\operatorname{root}(\mathrm{B})$ dry biomass of alfalfa plant grown under ZnO-NPs stress. Values are expressed as means standard deviation $(n=3)$; different small letters indicate significant difference at 0.05 level. 


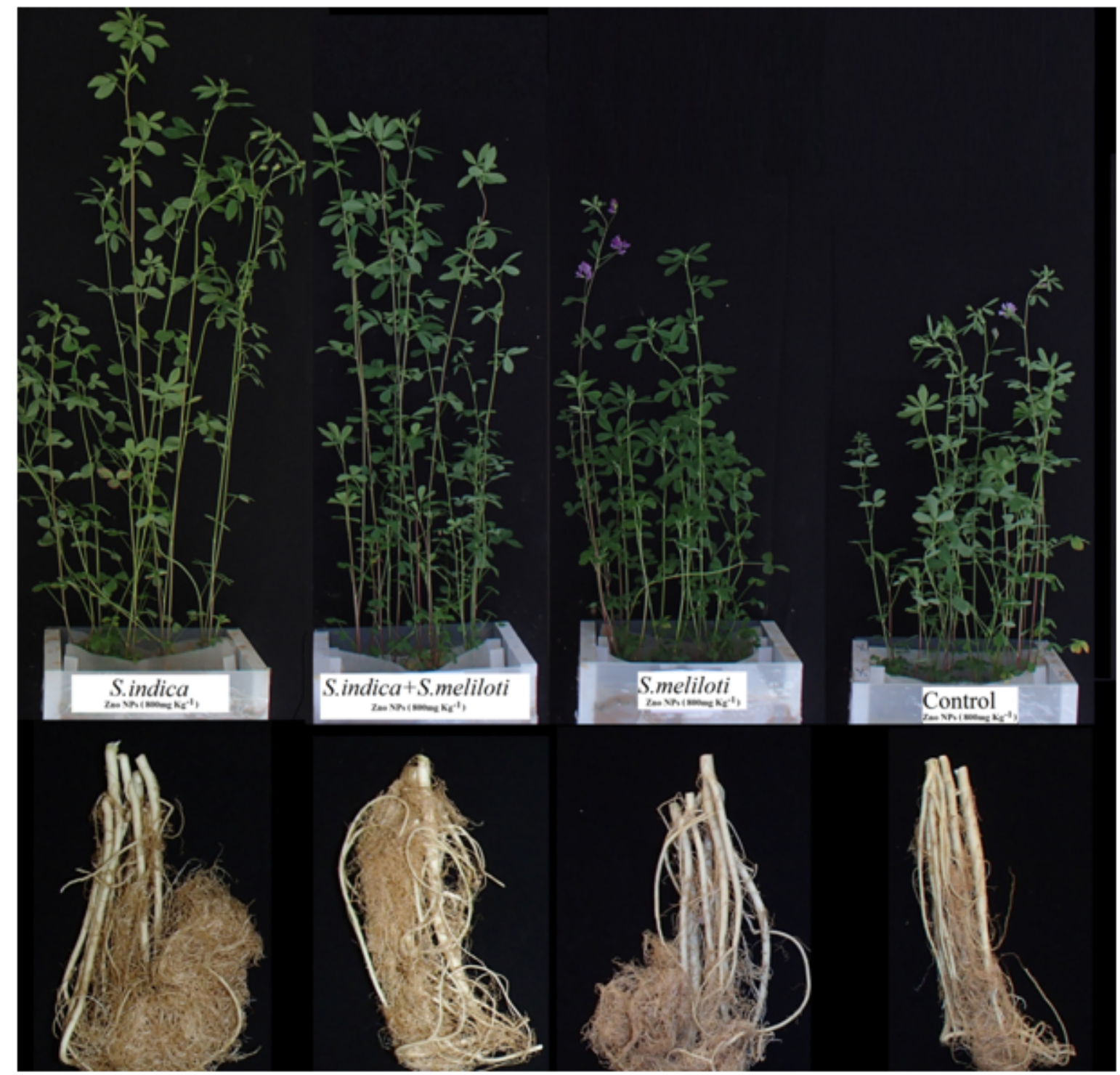

\section{Figure 2}

Effect of microbial inoculation on the shoot and root biomass of alfalfa plant exposed to $800 \mathrm{mg} \mathrm{Kg-1} \mathrm{ZnO-}$ NPs. 

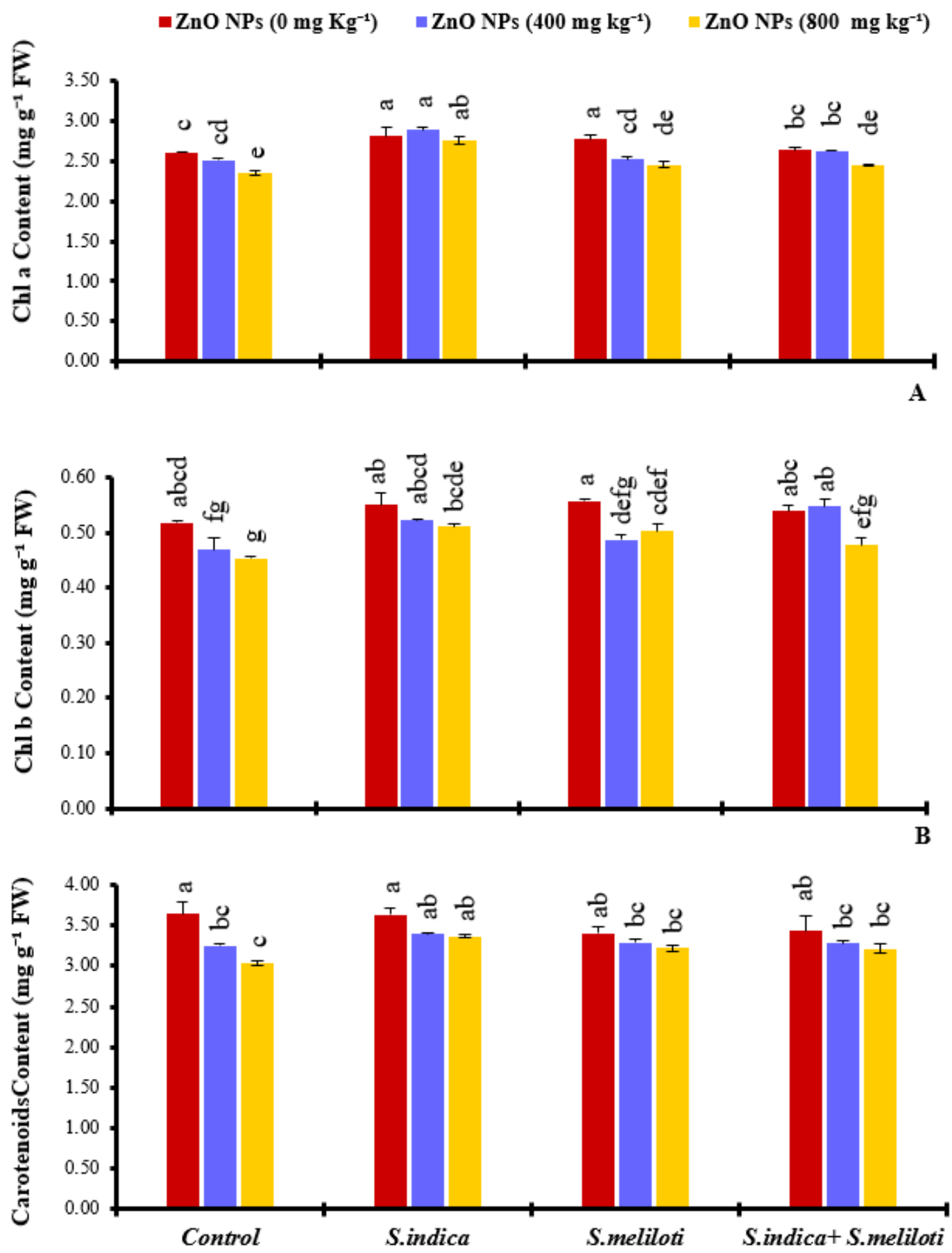

$\mathbf{C}$

Figure 3

Effect of microbial inoculation on chlorophyll (chl) content a (A) and b (B) and carotenoids content (C) of alfalfa plant grown under ZnO-NPs stress. Values are expressed as means standard deviation $(n=3)$; different small letters indicate significant difference at 0.05 level. 
$\square \mathrm{ZnO}$ NPs $\left(0 \mathrm{mg} \mathrm{Kg}^{-1}\right) \quad \square \mathrm{ZnO} \mathrm{NPs}\left(400 \mathrm{mg} \mathrm{kg}^{-1}\right) \quad \square \mathrm{ZnO}$ NPs $\left(800 \mathrm{mg} \mathrm{kg}^{-1}\right)$
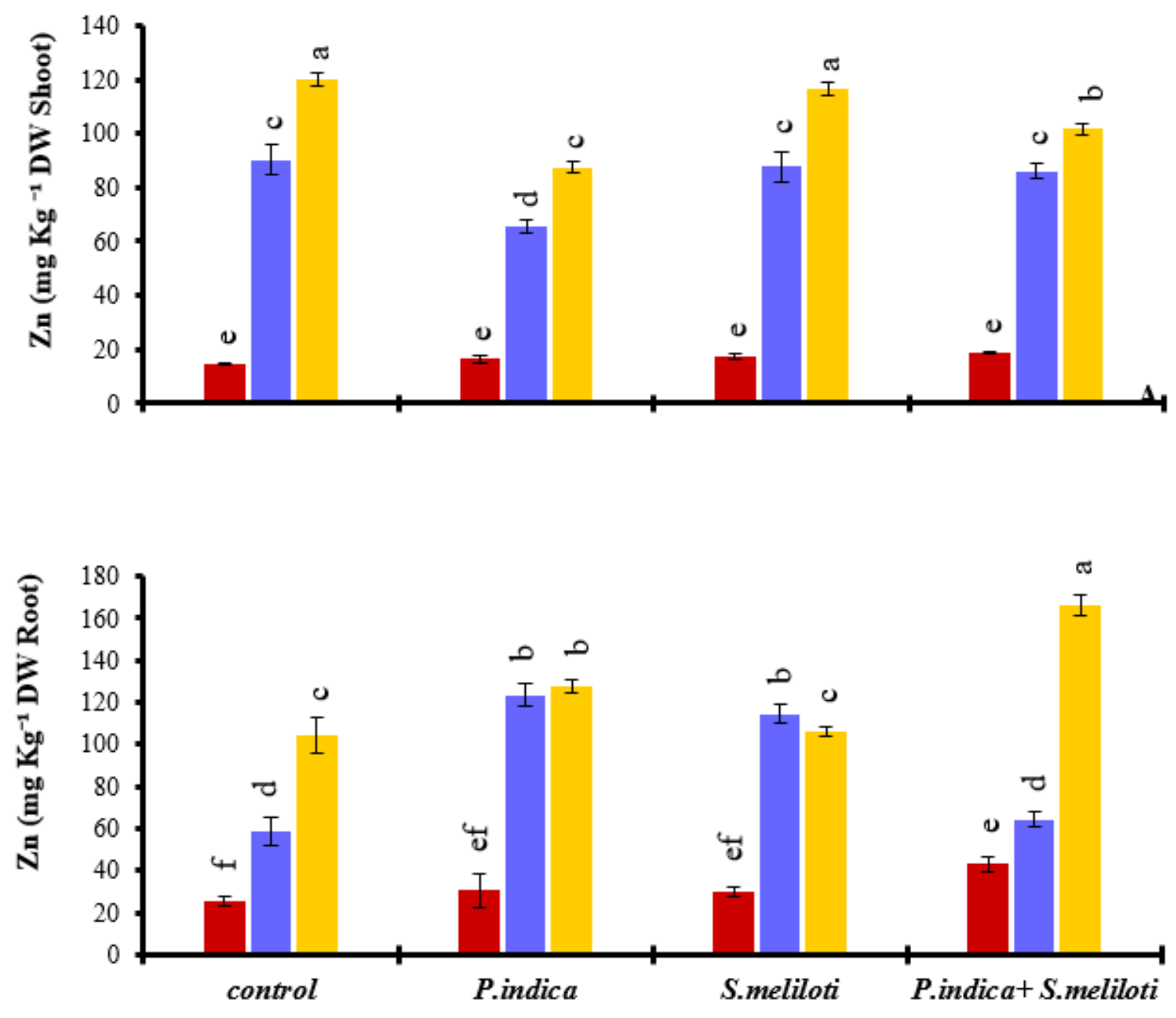

B

Figure 4

Effect of microbial inoculation on the concentration of $\mathrm{Zn}$ in the shoot $(A)$ and root $(B)$ of alfalfa plant grown under ZnO-NPs stress. Values are expressed as means standard deviation $(n=3)$, different small letters indicate significant difference at 0.05 level. 


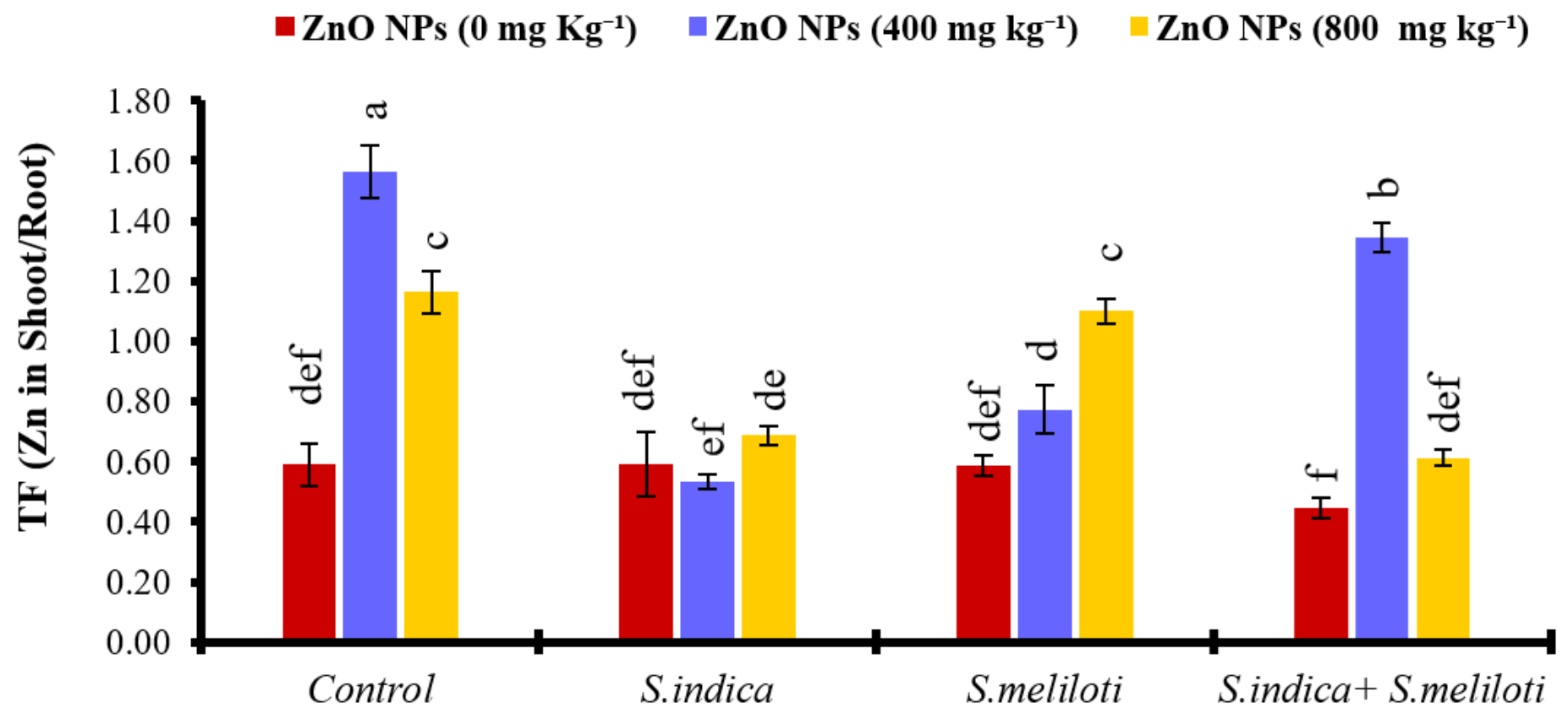

Figure 5

Effect of microbial inoculation on the translocation factor (TF ration $\mathrm{Zn}$ content in shoot to $\mathrm{Zn}$ content in root) of alfalfa plant grown under ZnO-NPs stress. Values are expressed as means standard deviation ( $n=3)$; different small letters indicate significant difference at 0.05 level. 

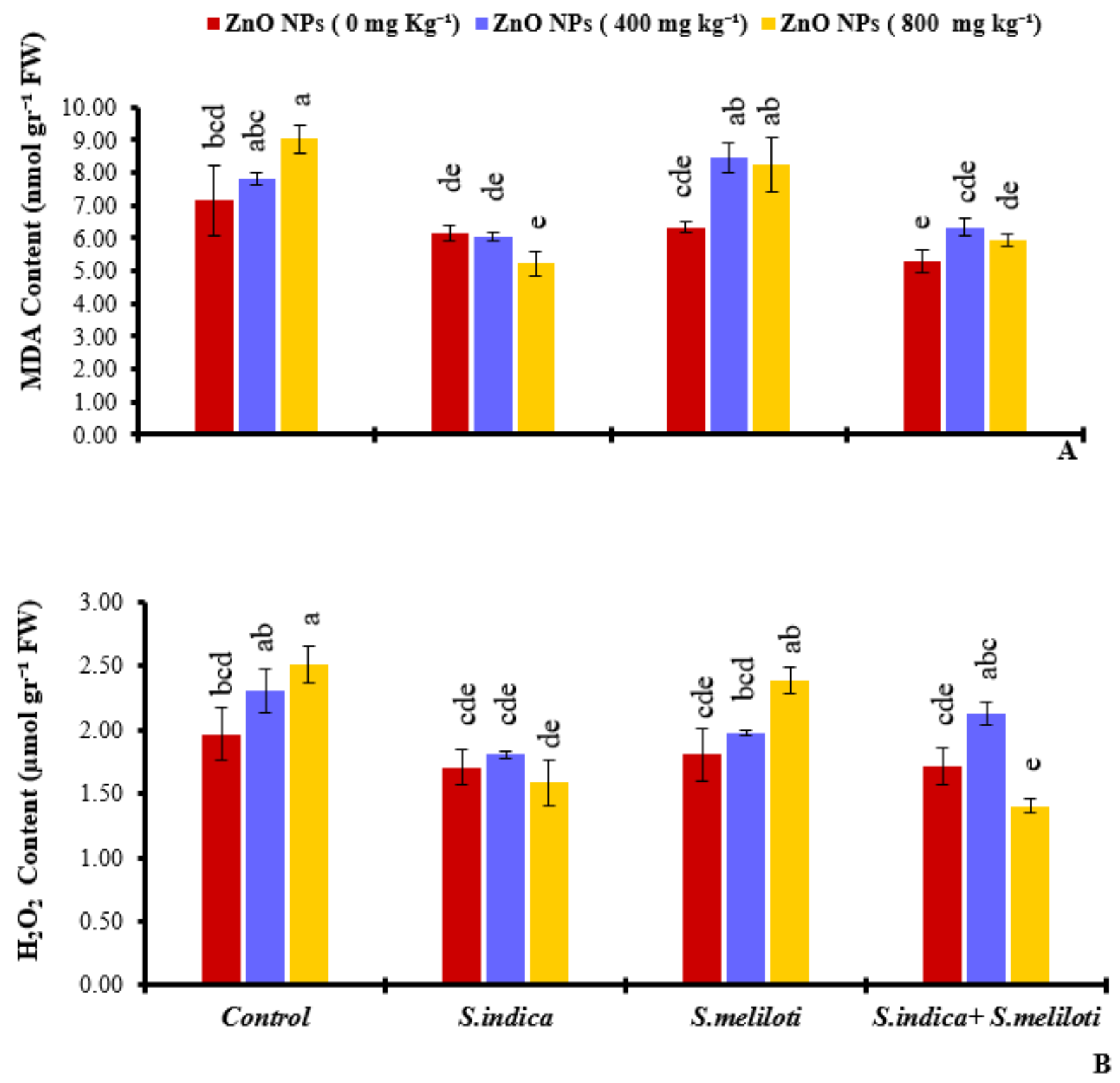

Figure 6

Effect of microbial inoculation on the Malondialdehyde (A) and hydrogen peroxide (B) contents of alfalfa plant leaves grown under ZnO-NPs stress. Values are expressed as means standard deviation ( $n=3)$; different small letters indicate significant difference at 0.05 level.

\section{Supplementary Files}

This is a list of supplementary files associated with this preprint. Click to download.

- GraphicalAbstract.pptx 